\title{
Early activation of peripheral monocytes with hallmarks of M1 and M2 monocytic cells in excessive alcohol drinkers: a pilot study
}

\author{
Crystal C Walline, ${ }^{1}$ Janice S Blum, ${ }^{2}$ Tobyn Linton, ${ }^{3}$ Darrin Mangiacarne, ${ }^{3}$ \\ Suthat Liangpunsaku| ${ }^{4,5,6}$
}

'Department of Biology, University of North Carolina, Pembroke, North Carolina, USA

${ }^{2}$ Department of Microbiology and Immunology, Indiana University School of Medicine, Indianapolis, Indiana, USA

${ }^{3}$ Fairbanks Drug and Alcohol Rehabilitation, Indianapolis, Indiana, USA

${ }^{4}$ Division of

Gastroenterology and

Hepatology, Department of Medicine, Indiana University School of Medicine, Indianapolis, Indiana, USA

${ }^{5}$ Roudebush Veterans Administration Medical Center, Indianapolis, Indiana, USA

${ }^{6}$ Department of Biochemistry and Molecular Biology, Indiana University School of Medicine, Indianapolis, Indiana, USA

\section{Correspondence to} Dr Suthat Liangpunsakul, Division of Gastroenterology and Hepatology, Department of Medicine, Indiana University School of Medicine, Indianapolis, IN 46202, USA:

sliangpu@iu.edu

Received 26 December 2017 Revised 11 February 2018 Accepted 17 February 2018

\section{Check for updates}

To cite: Walline CC, Blum JS, Linton T, et al. $J$ Investig Med Epub ahead of print: [please include Day Month Year] doi:10.1136/jim-2017000706

\section{ABSTRACT}

Excessive drinking can lead to the development of immune dysfunction. Our aim is to investigate the effect of alcohol on immune activation from circulating peripheral blood monocytes in excessive drinkers (EDs). Twenty-two EDs and healthy controls were enrolled. Time line follow-back was used to quantify the amount of alcohol consumed in the past 30 days before enrollment. Peripheral bloodderived $\mathrm{CD} 14^{+}$monocytes were isolated for gene expression analyses. Serum interleukin (IL)-6, IL-10 and lipopolysaccharides (LPS) were also measured. We found that serum LPS concentrations were significantly higher in EDs compared with controls $(P<0.05)$. While no differences in the levels of circulating IL-6 and IL-10 were observed, the relative levels of gene transcripts $(R Q)$ for $1 / 6$ (an M1-polarizing cytokine) and I/10 (an M2-polarizing cytokine) were significantly higher in peripheral blood-derived monocytes from EDs compared with controls (//6: $P<0.01$. I/10: $P<0.05)$. EDs exhibit early immune activation of peripheral blood monocyte mRNA transcripts, notably $\| 6$ and $\| 10$. Future studies are needed to explore the clinical implications of our findings and determine whether the levels of $/ / 6$ and $/ / 10$ mRNA expression can be used to identify those with excessive drinking and to monitor for alcohol abstinence.

\section{INTRODUCTION}

Endotoxin (or lipopolysaccharides (LPS)) is an important factor driving the pathogenesis of alcohol-induced liver injury. ${ }^{1-3}$ The changes in innate and adaptive immunity in response to LPS can have a profound effect on the severity and progression of alcoholic liver disease (ALD). ${ }^{2}$ Serum levels of pro-inflammatory cytokines interleukin- $1 \alpha$ (IL- $1 \alpha)$, IL- $1 \beta$, IL-6 and tumor necrosis factor alpha (TNF $\alpha)$ increase in patients with ALD, and elevated IL-6 is correlated with increased mortality. ${ }^{45}$ This pilot study was designed to investigate if changes in innate immune activation could be detected in patients with excessive alcohol use compared with healthy controls. The plasma levels of IL-6 and IL-10 in these subjects were normal, despite having elevated serum LPS levels. However, early signs of innate immune cell activation were detectable in peripheral blood monocytes as evidenced by increased $I l 6$ and Il10 gene expression. These data indicate evaluating a limited number of gene transcripts as a measure of monocyte activation could be of use to detect early immune system dysfunction in patients with excessive alcohol use.

\section{MATERIALS AND METHODS}

\section{Human subject recruitment}

Twenty-two excessive drinkers (EDs) who were seen at the Fairbanks Drug and Alcohol Treatment Center (Indianapolis, Indiana, USA) were enrolled. All met the criteria for 'excessive drinking' according to the National Institute of Health/National Institute on Alcohol Abuse and Alcoholism; which are defined as men who drink $>4$ standard drinks in a day (or $>14$ per week) and women who drink $>3$ standard drinks in a day (or $>7$ per week). ${ }^{6}$ Twenty non-EDs (healthy controls) without known medical or surgical histories were recruited from Richard L. Roudebush Veterans Administration Medical Center in Indianapolis, Indiana. All participants were at least 21 years of age and provided informed consent.

\section{Endotoxin assay}

The Endpoint Chromogenic Limulus Amebocyte Lysate test was used to detect LPS endotoxin (Lonza, Allendale, New Jersey, USA).

\section{Analysis for plasma IL-6 and IL-10}

ELISAs were performed using Costar EIA/ RIA flat-bottomed 96-well plates coated over night with capture antibody diluted in $0.1 \mathrm{M}$ carbonate buffer, $\mathrm{pH}$ 9.5. For the remaining steps, all antibodies and human plasma were diluted in phosphate buffered saline (PBS)/1 per cent bovine serum albumin. IL- 6 and IL-10 were measured in plasma using a standard ELISA with $2 \mu \mathrm{g} / \mathrm{mL}$ purified and $1 \mu \mathrm{g} / \mathrm{mL}$ biotinylated antibodies (BD Biosciences, San Jose, California, USA) and streptavidin-horseradish peroxidase (Thermo Fisher Scientific).

\section{Quantitative real-time PCR (qRT-PCR)}

Blood was collected in tubes containing sodium heparin (Becton Dickinson), rested overnight at 
$22-25^{\circ} \mathrm{C}$, and centrifuged at $2000 \mathrm{rpm}$ for $10 \mathrm{~min}$ at $22^{\circ} \mathrm{C}$; plasma was removed and stored at $-80^{\circ} \mathrm{C}$ until use. One part blood was diluted with one part room temperature PBS. One part Ficoll-Hypaque was layered underneath the blood/PBS mixture and centrifuged at $1600 \mathrm{rpm}$ for $30 \mathrm{~min}$ at $22^{\circ} \mathrm{C}$. The polymorphonuclear cell $(\mathrm{PMN})$ layer was removed, washed two times with $4^{\circ} \mathrm{C}$ PBS and counted. Typical recovery was 1 to $3 \times 10^{6} \mathrm{PMNs}$ per milliliter blood, and viability was determined by the Trypan blue exclusion method and was generally $>95$ per cent. Cells were separated into $\mathrm{CD} 14^{+}$mononuclear and $\mathrm{CD} 14^{-}$non-mononuclear fractions using the Human Pan Monocyte Isolation Kit (Miltenyi Biotec, Auburn, California, USA). Cells were flash frozen and stored at $-80^{\circ} \mathrm{C}$ until use. Total RNA was extracted (RNeasy Mini kit, Qiagen, Valencia, California, USA) and cDNA was generated using the High-capacity cDNA Reverse Transcription Kit; qRT-PCR was performed using commercially available TaqMan primers and the ABI Prism 7500 Fast RT-PCR System (Applied Biosystems, Carlsbad, California, USA). Gene expression was quantitated relative to beta- 2 microglobulin mRNA levels and presented as an arbitrary fold change compared with control samples.

\section{Statistical analyses}

Statistical significance was determined using the non-parametric Mann-Whitney test with a confidence level of 95 per cent (GraphPad Prism V.6.02). ${ }^{*} \mathrm{P}<0.05 ; * * \mathrm{P}<0.01$.

\section{RESULTS}

\section{Study cohort characteristics}

The clinical characteristics of the study patients are shown in table 1. As expected, EDs had significantly higher Alcohol Use Disorders Identification Test (AUDIT) scores (27.4 \pm 8.1 vs $3.3 \pm 3.1, \mathrm{P}<0.001)$ and higher alcohol consumption over the last 30 days $(242.5 \pm 130$ vs $9.9 \pm 15.1$ standard drinks, $\mathrm{P}<0.001)$ compared with controls. There was no significant difference in the levels of gamma-glutamyl transpeptidase (GGT), aspartate aminotransferase (AST) or alanine aminotransferase (ALT) levels between groups. EDs had higher levels of serum CDT $(3.0 \pm 0.8$ vs $1.6 \pm 0.5, \mathrm{P}=0.02)$.

\section{Levels of LPS, IL- 6 and IL-10 in EDs and controls}

The levels of serum LPS in EDs were significantly higher than those in controls $(0.26 \pm 0.07$ vs $0.13 \pm 0.03 \mathrm{EU} / \mathrm{mL}$, $\mathrm{P}<0.05)$. We next measured the LPS-induced production of cytokines, including IL-6 and IL-10. Interestingly, despite the increased in serum LPS in EDs, we did not observe a difference in the plasma levels of IL-6 (470 \pm 484 vs $615 \pm 742 \mathrm{pg} / \mathrm{mL}$, in controls and EDs, respectively, P>0.05) and IL-10 (254 \pm 172 vs EDs: $365 \pm 484 \mathrm{pg} / \mathrm{mL}$, $\mathrm{P}>0.05$ ) between these two groups.

\section{Early activations of innate immune response in EDs and controls}

To determine if early activation of the innate immune system could be detected in EDs due to the increase in the levels of serum LPS, we measured the relative expression of mRNAs for monocyte differentiation markers and cytokines in peripheral blood-derived $\mathrm{CD} 14^{+}$monocytes using qRT-PCR. While we did not observe a difference in the
Table 1 Selected demographic, clinical and laboratory characteristics of the study cohort

\begin{tabular}{|c|c|c|c|}
\hline & $\begin{array}{l}\text { Health controls } \\
(\mathrm{N}=20)\end{array}$ & $\begin{array}{l}\text { Excessive } \\
\text { drinkers }(\mathrm{N}=20)\end{array}$ & $P$ values \\
\hline Age (years) & $30.7 \pm 9.1$ & $36.9 \pm 10.0$ & 0.05 \\
\hline Males (N, \%) & $17(85)$ & $15(69)$ & 0.18 \\
\hline Race (Caucasian, N, \%) & $13(65)$ & $17(77)$ & 0.62 \\
\hline Smoking (N, \%) & $14(70)$ & $15(68)$ & 1.00 \\
\hline Height (cm) & $178.5 \pm 7.7$ & $172.9 \pm 8.1$ & 0.06 \\
\hline Weight (kg) & $78.2 \pm 8.7$ & $77.5 \pm 9.8$ & 0.39 \\
\hline BMI $\left(\mathrm{kg} / \mathrm{m}^{2}\right)$ & $29.1 \pm 5.3$ & $26.1 \pm 3.5$ & 0.09 \\
\hline Waist circumference $(\mathrm{cm})$ & $103.1 \pm 15.9$ & $93.1 \pm 10.0$ & 0.06 \\
\hline AUDIT-C scores & $3.3 \pm 3.1$ & $27.4 \pm 8.1$ & $<0.001$ \\
\hline $\begin{array}{l}\text { Total standard drinks last } \\
30 \text { days }\end{array}$ & $9.9 \pm 15.1$ & $242.5 \pm 130.0$ & $<0.001$ \\
\hline AST (U/L) & $31.1 \pm 17.3$ & $23.5 \pm 7.1$ & 0.15 \\
\hline ALT (U/L) & $22.2 \pm 16.5$ & $25.2 \pm 11.5$ & 0.26 \\
\hline Albumin (g/dL) & $4.1 \pm 0.2$ & $3.7 \pm 0.4$ & 0.03 \\
\hline Total protein (g/dL) & $7.8 \pm 0.6$ & $6.4 \pm 0.6$ & $<0.01$ \\
\hline GGT (U/L) & $29.0 \pm 13.4$ & $32.3 \pm 24.1$ & 0.63 \\
\hline$\%$ CDT & $1.6 \pm 0.5$ & $3.0 \pm 0.8$ & 0.02 \\
\hline Serum LPS (EU/mL) & $0.13 \pm 0.03$ & $0.26 \pm 0.07$ & $<0.05$ \\
\hline Plasma IL-6 (pg/mL) & $470 \pm 484$ & $615 \pm 742$ & 0.09 \\
\hline Plasma IL-10 (pg/mL) & $254 \pm 172$ & $365 \pm 484$ & 0.10 \\
\hline
\end{tabular}

ALT, alanine aminotransferase; AST, aspartate aminotransferase; AUDIT-C, Alcohol Use Disorders Identification Test; BMI, body mass index; CDT, carbohydrate-deficient transferrin; GGT, gamma-glutamyl transpeptidase; IL, interleukin; LPS, lipopolysaccharides.

plasma levels of IL-6 and IL-10, we found that Il6 (associated with M1-polarization) and Il10 (associated with M2-polarization) gene transcripts were significantly increased in EDs compared with controls (figure 1A,B). However, we did not find a difference in transcript levels for other M1 monocyte differentiation markers (Il1b, Tnf and Ccl2) and membrane protein markers of the M2 phenotype (mannose receptor (Mrc1)) (figure 1C-G). Lastly, despite increased serum LPS, EDs did not have the alteration in the gene expression of toll-like receptor 4 , the binding target of LPS (figure $1 \mathrm{H}$ ). These results indicate that excessive alcohol consumption leads to an early activation of peripheral monocytes with increased transcription of a limited subset of hallmark cytokines $I l 6$ and $I l 10$.

\section{DISCUSSION}

Circulating monocytes and macrophages are acutely sensitive to changes in metabolites and nutrients, inflammatory stimuli and tissue damage. ${ }^{7}$ We recently reported an increase in the levels of LPS and markers of monocyte activations, notably soluble CD14 and soluble CD163 among EDs. ${ }^{3}$ At the cellular levels, a subset of circulating monocytes and macrophages has been identified and distinguished based on transcriptional profiles, cell surface marker expression and functions, such as cytokine and chemokine release. ${ }^{78}$ At the extremes are dedicated M1 cells associated with the production of pro-inflammatory cytokines (eg, IL-6) and pathogen clearance. ${ }^{9}$ Conversely, M2 cells mediate immune suppression and tissue remodeling/regeneration. ${ }^{9}$ Illo gene expression is associated with M2 cells depending on the context of co-expressed signaling molecules. ${ }^{8}$ Changes in 

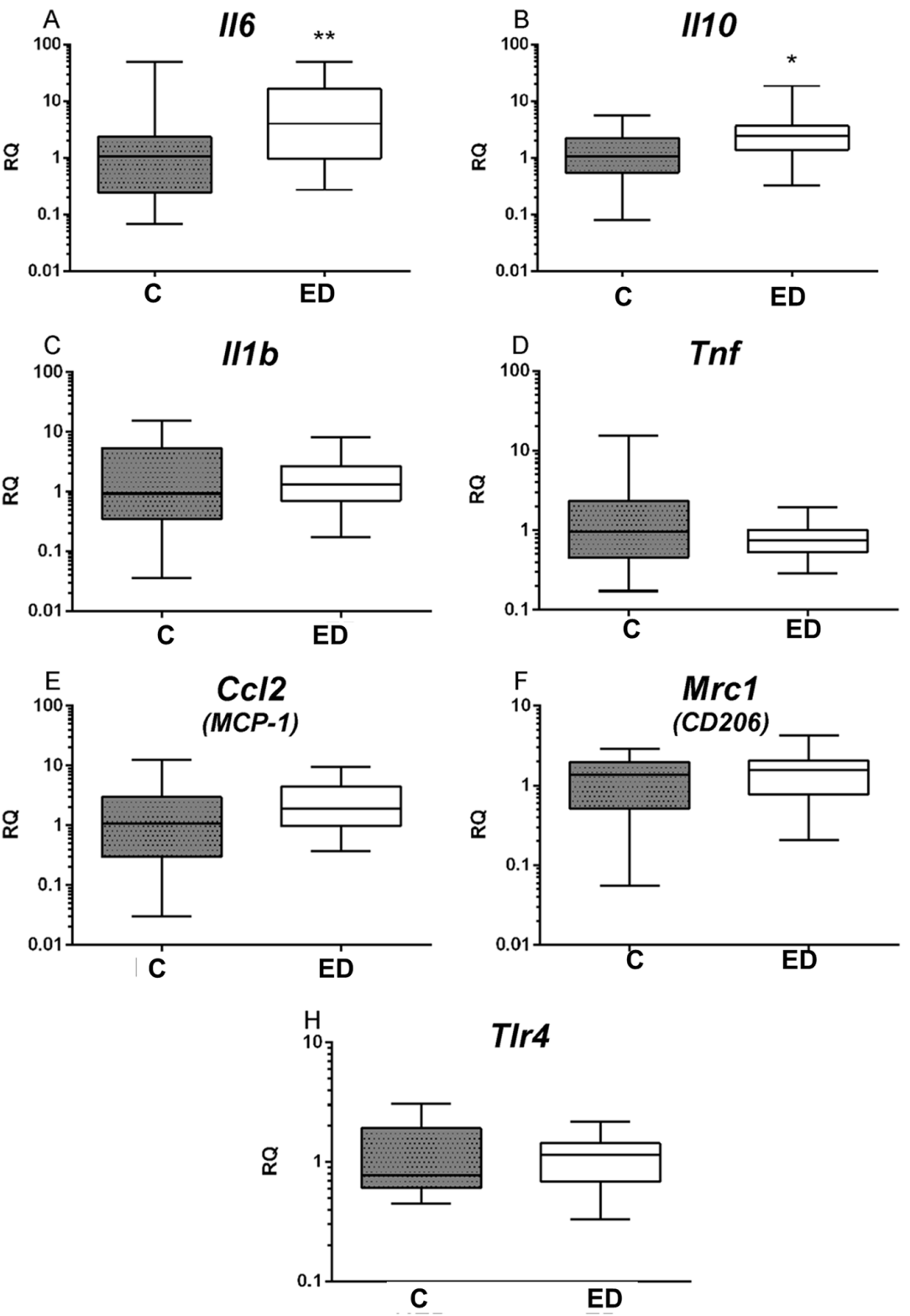

Figure 1 Excessive alcohol drinking induces increased expression of //6 and //10 gene transcripts in peripheral blood monocytes. CD14 ${ }^{+}$ monocytes were separated from other polymorphonuclear cell with the Human Pan Monocyte Isolation Kit. Total RNA from CD14 ${ }^{+}$ monocytes was reverse transcribed and analyzed by $\mathrm{qRT}-\mathrm{PCR}$ for expression of monocyte/macrophage differentiation markers. The relative expression of $/ / 6$ and $/ / 10$ gene transcripts were significantly increased in the excessive drinkers (ED) compared with controls (C) (//6, $\left.{ }^{*} P<0.01 ; / / 10,{ }^{*} P<0.05\right)$. RQ, Relative quantification.

serum IL-6 and IL-10 production from activated, circulating monocytes/macrophages are observed in several inflammatory disorders including multiple sclerosis, type 1 and type 2 diabetes, metabolic syndrome, obesity, non-alcoholic fatty liver disease and ALD. ${ }^{10-14}$

In EDs, CD14 ${ }^{+}$peripheral blood monocytes displayed a significant increase in Il6 and Il10 transcripts. We did not distinguish whether this reflects the presence of multiple distinct monocyte subsets or a continuum of circulating monocytic cells. However, Kupffer cells, the resident liver macrophages, produce both IL-6 and IL-10 as an innate immune response to liver damage. ${ }^{15} 16$ LPS stimulation of Kupffer cells induces IL-6 production which transiently activates STAT3, leading to the production of pro-inflammatory cytokines. ${ }^{2}$ In contrast, IL-6 can also activate hepatocytes, hepatic stellate cells and sinusoidal endothelial cells which result in downstream signaling that protects against liver injury, promotes liver regeneration and regulates liver fibrosis and inflammation. ${ }^{17-19}$ IL-10 causes a prolonged activation of STAT3 in Kupffer cells, leading to an anti-inflammatory response by attenuating LPS, TNF $\alpha$ and complement activation, resulting in dampened liver inflammation. ${ }^{217}$ The interplay of IL- 6 and IL-10 in liver inflammation and disease has been demonstrated in animal studies. ${ }^{20}{ }^{21}$ Although IL-10 is associated with anti-inflammatory effects, the immune suppressing effects of prolonged IL-10 production may enhance the susceptibility of heavy drinkers to viruses such as hepatitis 
B or HIV, as IL-10 appears to favor virus infection and persistence. $^{22} 23$

The strengths of this study are the prospective design and the well-characterized cohort of EDs. However, our pilot study consisted of a small sample size. Future studies in a larger cohort are needed to confirm our observation. In addition, a recent study demonstrated that the increase in immune/inflammatory changes in response to the LPS is more prominent in female drinkers. ${ }^{24}$ The study design to explore the gender differences in the expression of the gene transcript on peripheral blood mononuclear cells in responses to alcohol is warranted.

In summary, our pilot study suggested that the changes in the Il6 and Il10 transcripts (in the absence of elevated plasma/serum cytokines) may be an early indicator of metabolic change associated with excessive alcohol consumption. Future studies are needed to explore the clinical implications of our findings and determine whether the levels of Il6 and Il10 mRNA expression can be used to identify those with excessive drinking and to monitor for alcohol abstinence.

Contributors Conceived and designed the experiments and wrote the paper: CCW, JB and SL. Subject recruitment: TL and DM. Performed the experiments and analyzed the data: CCW and SL. Contributed reagents/materials/analysis tools: JB and SL. All authors have read and approved the final draft of the manuscript.

Funding This research was supported by the United States National Institutes of Health under award numbers P01 Al056097 (JSB), T32 HL007910 (CCW), K08 AA016570, 1101CX000361-W81XWH-12-1-0497 from United States Department of Defense, NIH U01AA021840, NIH R21AA024935, NIH R01 DK107682, NIH R01 AA025208, and the Showalter Scholar Award from the Ralph W. and Grace M. Showalter Research Trust (all to $S L)$.

Disclaimer The funders had no role in study design, data collection and analysis, decision to publish, or preparation of the manuscript.

Competing interests None declared.

\section{Patient consent Obtained.}

Ethics approval The study design and protocol were approved by the Institutional Review Board at the Indiana University Purdue University Indianapolis (IUPUI), Richard L. Roudebush VAMC Research and Development Program and at Fairbanks Alcohol Rehabilitation Center.

Provenance and peer review Not commissioned; externally peer reviewed.

C American Federation for Medical Research (unless otherwise stated in the text of the article) 2018. All rights reserved. No commercial use is permitted unless otherwise expressly granted.

\section{REFERENCES}

1 Gao B, Bataller R. Alcoholic liver disease: pathogenesis and new therapeutic targets. Gastroenterology 2011;141:1572-85.

2 Gao B, Seki E, Brenner DA, et al. Innate immunity in alcoholic liver disease. Am J Physiol Gastrointest Liver Physiol 2011;300:G516-G525.
3 Liangpunsakul S, Toh E, Ross RA, et al. Quantity of alcohol drinking positively correlates with serum levels of endotoxin and markers of monocyte activation. Sci Rep 2017;7:4462.

4 Nicolaou C, Chatzipanagiotou S, Tzivos D, et al. Serum cytokine concentrations in alcohol-dependent individuals without liver disease. Alcohol 2004;32:243-7.

5 Sheron N, Bird G, Goka J, et al. Elevated plasma interleukin-6 and increased severity and mortality in alcoholic hepatitis. Clin Exp Immunol 1991;84:449-53.

6 US Department of Health and Human Services. Helping Patients who drink too much. A clinician's guide. 2005 Edition. USA: National Institute of Health/ National Institute on Alcohol Abuse and Alcoholism, 2005.

7 Yang J, Zhang L, Yu C, et al. Monocyte and macrophage differentiation: circulation inflammatory monocyte as biomarker for inflammatory diseases. Biomark Res 2014;2:1.

8 Ju C, Liangpunsakul S. Role of hepatic macrophages in alcoholic liver disease. J Investig Med 2016;64:1075-7.

9 Murray PJ, Wynn TA. Protective and pathogenic functions of macrophage subsets. Nat Rev Immunol 2011;11:723-37.

10 Hillenbrand A, Knippschild U, Weiss M, et al. Sepsis induced changes of adipokines and cytokines - septic patients compared to morbidly obese patients. BMC Surg 2010;10:26.

11 Odegaard Jl, Chawla A. Alternative macrophage activation and metabolism. Annu Rev Pathol 2011;6:275-97.

12 Espinoza-Jiménez A, Peón AN, Terrazas LI. Alternatively activated macrophages in types 1 and 2 diabetes. Mediators Inflamm 2012;2012:1-10.

13 Li W, Amet T, Xing Y, et al. Alcohol abstinence ameliorates the dysregulated immune profiles in patients with alcoholic hepatitis: a prospective observational study. Hepatology 2017;66:575-90.

14 Chuluundorj D, Harding SA, Abernethy D, et al. Expansion and preferential activation of the CD14(+)CD16(+) monocyte subset during multiple sclerosis. Immunol Cell Biol 2014;92:509-17.

15 Latvala J, Hietala J, Koivisto $\mathrm{H}$, et al. Immune responses to ethanol metabolites and cytokine profiles differentiate alcoholics with or without liver disease. Am J Gastroenterol 2005;100:1303-10.

16 Knolle P, Schlaak J, Uhrig A, et al. Human Kupffer cells secrete IL-10 in response to lipopolysaccharide (LPS) challenge. J Hepatol 1995;22:226-9.

17 Gao B. Hepatoprotective and anti-inflammatory cytokines in alcoholic liver disease. J Gastroenterol Hepatol 2012;27(Suppl 2):89-93.

18 Sun Z, Klein AS, Radaeva S, et al. In vitro interleukin-6 treatment prevents mortality associated with fatty liver transplants in rats. Gastroenterology 2003:125:202-15.

19 Miller AM, Wang H, Park O, et al. Anti-inflammatory and anti-apoptotic roles of endothelial cell STAT3 in alcoholic liver injury. Alcohol Clin Exp Res 2010;34:719-25.

20 Hong F, Kim WH, Tian Z, et al. Elevated interleukin-6 during ethanol consumption acts as a potential endogenous protective cytokine against ethanol-induced apoptosis in the liver: involvement of induction of $\mathrm{BCl}-2$ and $\mathrm{BCl}-\mathrm{x}(\mathrm{L})$ proteins. Oncogene 2002;21:32-43.

21 El-Assal O, Hong F, Kim WH, et al. IL-6-deficient mice are susceptible to ethanol-induced hepatic steatosis: IL-6 protects against ethanol-induced oxidative stress and mitochondrial permeability transition in the liver. Cell Mol Immunol 2004;1:205-11.

22 Das A, Ellis G, Pallant C, et al. IL-10-producing regulatory B cells in the pathogenesis of chronic hepatitis B virus infection. J Immunol 2012;189:3925-35.

23 Fuster D, Cheng DM, Quinn EK, et al. Inflammatory cytokines and mortality in a cohort of HIV-infected adults with alcohol problems. AIDS 2014;28:1059-64.

24 Orio L, Antón M, Rodríguez-Rojo IC, et al. Young alcohol binge drinkers have elevated blood endotoxin, peripheral inflammation and low cortisol levels: neuropsychological correlations in women. Addict Biol 2017. 

with hallmarks of M1 and M2 monocytic cells in excessive alcohol drinkers: a pilot study

Crystal C Walline, Janice S Blum, Tobyn Linton, Darrin

Mangiacarne and Suthat Liangpunsakul

J Investig Med published online March 8, 2018

Updated information and services can be found at:

http://jim.bmj.com/content/early/2018/03/08/jim-2017-000706

\section{These include:}

References This article cites 22 articles, 2 of which you can access for free at:

http://jim.bmj.com/content/early/2018/03/08/jim-2017-000706\# ref-list-1

Email alerting Receive free email alerts when new articles cite this article. Sign service up in the box at the top right corner of the online article.

\section{Notes}

To request permissions go to:

http://group.bmj.com/group/rights-licensing/permissions

To order reprints go to:

http://journals.bmj.com/cgi/reprintform

To subscribe to BMJ go to:

http://group.bmj.com/subscribe/ 